\title{
GESTÃO DE RESÍDUOS QUÍMICOS EM UNIVERSIDADES: UNIVERSIDADE DE BRASÍLIA EM FOCO
}

\author{
Denise Imbroisi, Antônio José Moraes Guaritá-Santos*, Samantha Soares Barbosa, Susan da Fonseca Shintaku, Hugo \\ Jorge Monteiro, Gaston Alfredo East Ponce, Juliana Guadalupe Furtado, Carla Juliana Tinoco e Denise Carvalho Mello \\ Instituto de Química, Universidade de Brasília, CP 4417, 70919-970 Brasília-DF \\ Patrícia Fernandes Lootens Machado \\ Departamento de Química Inorgânica, Instituto de Química, Universidade Federal Fluminense, Outeiro de São João Batista, s/n, \\ 24020-150 Niterói - RJ
}

Recebido em 30/3/05; aceito em 30/6/05; publicado na web em 20/1/06

\begin{abstract}
MANAGEMENT OF CHEMICAL RESIDUES IN UNIVERSITIES: ASSESSING THE UNIVERSITY OF BRASÍLIA. The University of Brasília $(\mathrm{UnB})$ uses a diversity of chemical products, generating residues in a significant way in its multiple activities - teaching, research and community services. The UnB Comission on Chemical Residues Management was established in November 2002, aiming at three main objectives: 1) correct destination for the accumulated residues; 2) implantation of a chemical residues management system and 3) implantation of a UnB Unit for Treatment of Chemical Residues. To fulfil these commitments, a diagnosis of chemical residues produced by the University was performed, which is here presented with an evaluation of their future use, limitations and possibilities.
\end{abstract}

Keywords: chemical waste management; chemical residues in universities; environmental management of residues.

\section{INTRODUÇÃO}

A Universidade de Brasília (UnB) designou, em novembro de 2002, uma Comissão para Gestão de Resíduos Químicos da Universidade de Brasília (CGRQ-UnB), visando três objetivos básicos: destinação ambientalmente adequada do passivo acumulado; implementação de um sistema de gerenciamento de resíduos químicos e implementação da Central de Tratamento de Resíduos Químicos da UnB. O sistema de gestão tem por finalidade promover a redução e/ou eliminação do impacto ambiental causado pelo descarte inadequado dos resíduos químicos gerados pela UnB.

Devido às características de suas atividades - ensino, pesquisa e extensão - e ao número de pessoas atendidas nessas atividades, a UnB utiliza uma diversidade de produtos químicos, com conseqüente e significativa geração de resíduos. Essa diversidade de reagentes gera resíduos químicos que precisam ser descartados. Até o início da década de 90 não havia, na Universidade, nenhum sistema de gestão destes resíduos e sua quase totalidade era descartada, como na maioria das instituições públicas do país, da forma mais "fácil" possível: no esgoto ou lixo comum. Algumas iniciativas isoladas já eram executadas em diferentes instituições de ensino do país ${ }^{1,2}$. Inúmeras universidades brasileiras, conscientes de sua responsabilidade social e do papel que exercem na formação dos futuros profissionaiscidadãos, bem como dos danos ambientais provocados por um descarte inadequado de seus resíduos perigosos, iniciaram, desde então, programas de gerenciamento de resíduos ${ }^{3-8}$.

\section{HISTÓRICO}

$\mathrm{Na}$ UnB, a questão começou a ser tratada em 1994, quando se criou uma comissão para efetuar um diagnóstico dos resíduos perigosos da Instituição. Como resultado, em 1996 foi implantado um

\footnotetext{
*e-mail: resqui@unb.br
}

Programa de Gerenciamento de Resíduos Radioativos, tendo sido construído um depósito segundo orientações e cooperação técnica da Comissão Nacional de Energia Nuclear (CNEN). Este programa obteve pleno êxito e até a presente data funciona de maneira adequada.

Nessa mesma época - 1996, a Prefeitura do Campus (PRC) iniciou um trabalho de coleta dos resíduos químicos produzidos na Universidade de Brasília aproveitando, para isso, um antigo depósito de reagentes químicos e solventes, transformado em depósito "temporário" de resíduos. O trabalho de recolhimento foi iniciado devido a um crescente acúmulo de resíduos químicos armazenados nos laboratórios, uma vez que boa parte dos professores começou a estocar estes materiais na esperança de, eventualmente, poderem tratá-los ou destiná-los de maneira correta. No entanto, não foi proposta e executada nenhuma gestão do passivo recolhido.

É importante frisar que a ausência de gerenciamento acarretou um grave problema. Os resíduos eram levados para o depósito sem nenhum tipo de identificação. Este tipo de procedimento, de maneira geral, traz um grande risco de acumulação de materiais incompatíveis próximos uns dos outros. Por outro lado, como não existiam normas para coleta, qualquer tipo de material descartado pelo laboratório (gerador) era levado para o depósito. Era comum serem encontrados vários materiais de origem biológica - meios de cultura, soluções de bactérias, seringas, sangue etc - armazenados juntamente com resíduos químicos. Tudo isso já havia sido diagnosticado anteriormente por membros da equipe da Unidade de Tratamento de Resíduos Químicos da UnB - UTReQ, ${ }^{9,10}$.

Com um espaço de cerca de $58 \mathrm{~m}^{2}$, o depósito "temporário" de resíduos químicos logo foi abarrotado (Figura 1) e, como a produção de resíduos era contínua, a PRC viu-se obrigada a efetuar um descarte.

No início do ano 2000, em reunião conjunta com alguns órgãos do Governo do Distrito Federal (GDF), decidiu-se que o serviço de limpeza urbana do Distrito Federal ficaria responsável pela remoção dos resíduos acumulados. Assim, o material foi levado e pro- 


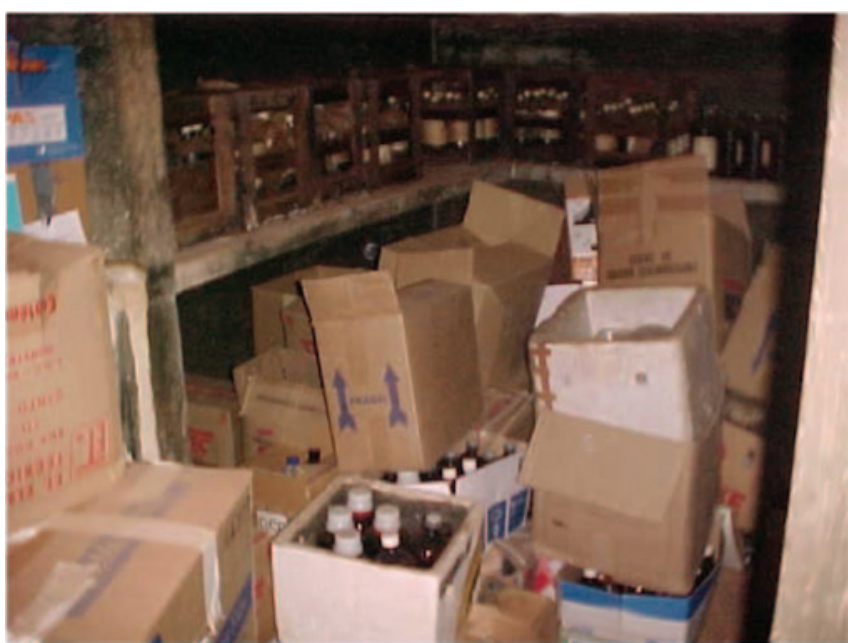

Figura 1. Situação do depósito de resíduos antes do programa de gerenciamento de resíduos químicos

vavelmente misturado com lixo comum, uma vez que no Distrito Federal não há um local adequado para incineração, nem aterro desse tipo de resíduo (classe I). Após este descarte (6000-8000 $\mathrm{kg}$ ), novo período de coletas foi iniciado.

Despertada para a situação, a Reitoria, em novembro de 2002 nomeou nova Comissão com a missão de implementar um sistema de gerenciamento dos resíduos químicos gerados na universidade e implantar uma Unidade de Tratamento de Resíduos Químicos. Com esta Unidade, a UnB espera atingir os mesmos níveis de redução já alcançados por outras instituições: reciclar $40 \%$ de seus resíduos, de forma que esta quantidade volte aos laboratórios como reagentes; tratar $40 \%$ de maneira adequada, para que possa ser descartada sem oferecer nenhum risco à sociedade e ao meio ambiente. Os $20 \%$ restantes seriam compostos por materiais sem condições de tratamento imediato e, portanto, seriam destinados a aterros específicos ou incinerados, por intermédio de empresa qualificada e possuidora de autorizações e licenciamentos ambientais específicos.

A primeira atividade desta nova comissão foi efetuar um diagnóstico da situação do depósito de resíduos químicos da UnB e a situação atual de seu passivo. No início de 2003 foi entregue à Reitoria o relatório deste diagnóstico, onde foram apresentados os problemas identificados pela Comissão, dentre os quais destacamos: coleta sem periodicidade definida; ausência de gerenciamento; armazenamento inadequado; falta de identificação em grande parte do material armazenado; reagentes descartados como resíduo; participação apenas de parte do total dos geradores; ausência de tratamento e, dificuldades para se efetuar a disposição final.

No entanto, os membros da CGRQ acreditaram ser possível transformar esta situação dramática em uma oportunidade para tornar a UnB uma universidade pioneira e de referência em gestão de resíduos químicos. Para isso, foram encaminhadas ações no sentido de se atender aos objetivos previstos para a Comissão. Desta forma, para normatizar a guarda e destinação dos resíduos químicos, a administração da UnB tomou a decisão política de assumir o compromisso de gerenciamento e tratamento destes resíduos, com destinação ambientalmente adequada do passivo existente no depósito.

Ressalta-se que o Programa de Gerenciamento de Resíduos Químicos da Universidade de Brasília deve ser entendido como parte das contribuições da Universidade para o cumprimento da Agenda 21 Local. Desta forma, destaca-se a importância do mesmo ser um programa de gerenciamento abrangente, incluindo dimensões econômicas e sociais, além da dimensão ecológica/ambiental.

\section{METODOLOGIA}

Dando início às atividades de implantação de um programa de gerenciamento dos resíduos químicos produzidos pela UnB, a CGRQ efetuou um diagnóstico da situação levantando, junto aos geradores, informações sobre geração, armazenagem e destinação de resíduos nas diferentes unidades. Um plano de gerenciamento de resíduos químicos no Campus Darcy Ribeiro também foi implementado, tendo sido várias etapas disponibilizadas para a comunidade universitária no site da Comissão para Gestão de Resíduos Químicos da UnB (www.unb.br/resqui).

Uma atividade complementar consistiu no esvaziamento parcial do depósito temporário pela remoção de frascos vazios e materiais biológicos ali incorretamente armazenados. Simultaneamente, por meio da disponibilização de página na Internet, a normatização de atividades do Programa de Gerenciamento foi iniciada. Técnicos responsáveis pelas atividades normatizadas pela CGRQ estão sendo treinados em cursos específicos, ministrados no âmbito da Comissão.

Os resíduos hospitalares e biológicos, contaminados ou não, foram incinerados por meio de um acordo entre a Universidade e a instituição responsável pelo gerenciamento de resíduos sólidos urbanos do Distrito Federal (Serviço de Ajardinamento e Limpeza Urbana do Distrito Federal - BELACAP) em um incinerador específico para resíduos oriundos de atividades dos serviços de saúde.

\section{Levantamento de informações junto aos geradores}

Um levantamento exaustivo com relação à utilização de substâncias químicas nos diversos laboratórios e setores da UnB e a geração de resíduos foi realizado durante o ano de 2003. Para este levantamento, foi elaborado um questionário contendo 10 perguntas (em anexo), aplicado por alunos bolsistas do Instituto de Química.

Procurou-se visitar pessoalmente cada laboratório e entrevistar seus responsáveis. Os laboratórios visitados estão situados no Campus Darcy Ribeiro e na Fazenda Água Limpa, de propriedade da UnB, tendo sido investigados cerca de $90 \%$ do número de laboratórios computados. Dificuldades em se contatar os responsáveis ou relacionadas ao difícil acesso impediram a obtenção de informações da totalidade dos laboratórios.

As respostas aos questionários foram tabuladas e alimentaram um banco de dados, em Excel, construído por participantes do projeto. Os dados foram tabulados a partir das unidades administrativas de menor porte (laboratórios) e depois consolidados em núcleos de complexidade crescente até se chegar a institutos e faculdades. Neste trabalho é apresentada apenas a consolidação final.

\section{RESULTADOS E DISCUSSÃO}

Para efetuar esta pesquisa, foram entrevistados preferencialmente técnicos responsáveis pelos respectivos laboratórios e professores; não havendo disponibilidade destes, recorreu-se a pós-graduandos ou alunos de graduação que estão a par das atividades efetuadas nos recintos em questão; estes se enquadram no campo "outros" do gráfico (Figura 2). Em muitos casos não foi especificada a função do entrevistado, estes equivalem a $28 \%$ no mesmo gráfico.

O levantamento de dados por questionário mostrou um panorama de reagentes utilizados e resíduos químicos gerados nas diversas atividades e áreas de trabalho da UnB, com um detalhamento ímpar para o caso de universidades brasileiras. Pesquisaram-se características dos laboratórios com relação a reagentes químicos 

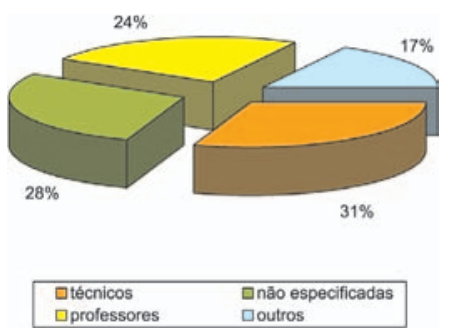

Figura 2. Funções dos entrevistados nos diversos laboratórios

e aos resíduos gerados. A Figura 3 mostra que 144 (cerca de 52\%) dos 278 laboratórios entrevistados usam produtos químicos em suas atividades.

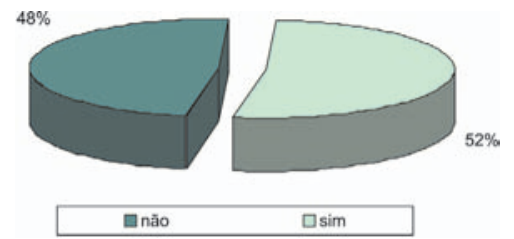

Figura 3. Utilização de reagentes químicos pelos laboratórios da UnB

Desses laboratórios, cerca de $31 \%$ dedicam-se somente à pesquisa e $54 \%$ trabalham tanto com pesquisa quanto com ensino, conforme apontado na Figura 4. Desta forma, antevê-se o gerenciamento dos resíduos produzidos nesses laboratórios como uma atividade de elevada complexidade, dada a diversidade de resíduos produzidos em pesquisa, visto que dinamicidade é uma característica intrínseca a processos de inovação e difusão tecnológicos.

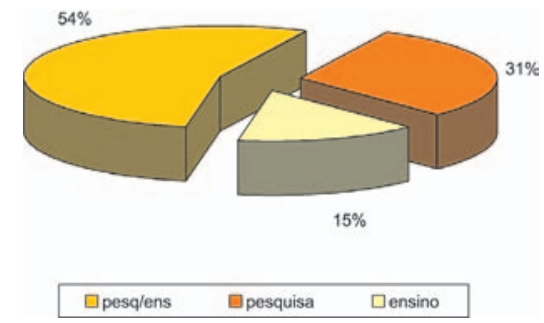

Figura 4. Atividades desenvolvidas nos laboratórios da UnB

Diversos produtos químicos são utilizados nos laboratórios da UnB. Ressalta-se que um mesmo laboratório pode utilizar mais de um tipo de substância. O item "outros", com expressivo valor (35\%), Figura 5, representa materiais químicos em que não se identificaram os componentes ou princípio ativo; ou ainda, materiais diversos não listados no questionário. Por ex.: produtos veterinários e de limpeza, medicamentos, pesticidas, revelador de filmes, psicotônicos, material radioativo, bactérias, cimento, óleos, resinas, gases.

Uma outra questão interessante refere-se ao armazenamento desses produtos antes de seu uso. Cerca de $3 / 4$ dos laboratórios que armazenam produtos químicos o fazem dentro do próprio laboratório (Figura 6). Vale destacar que alguns dos laboratórios, mesmo utilizando produtos químicos, não os armazenam, requisitando para seus trabalhos diários apenas a quantidade a ser utilizada. $\mathrm{O}$ item "outro local" refere-se a câmaras de refrigeração ou até salas de professores e outros laboratórios.

A Figura 7 lança luzes sobre um tema controverso: o que se faz com reagentes químicos com "data de validade" expirada? Segundo levantado pelas entrevistas, na UnB cerca de $35 \%$ são guardados para posterior recolhimento e cerca de $40 \%$ deles são utilizados. Embora este não seja um valor tão elevado, discute-se aqui se uma

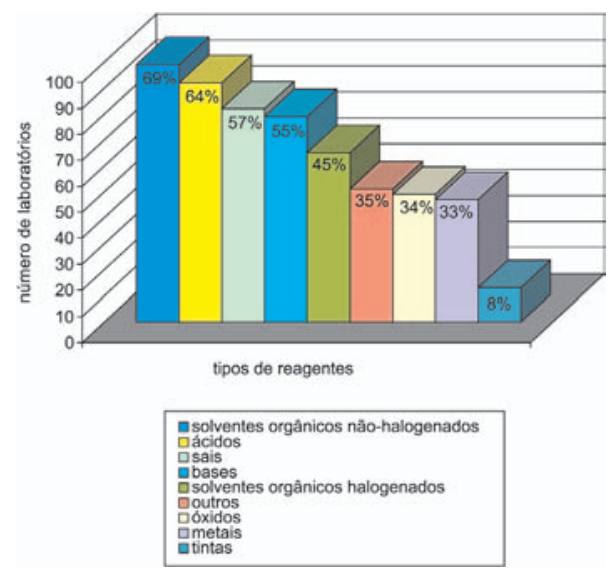

Figura 5. Produtos químicos utilizados nos laboratórios da UnB
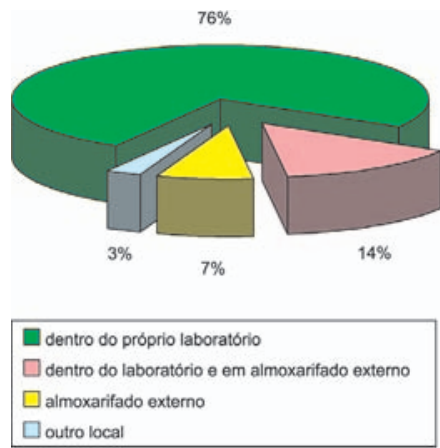

Figura 6. Local de armazenagem de reagentes químicos
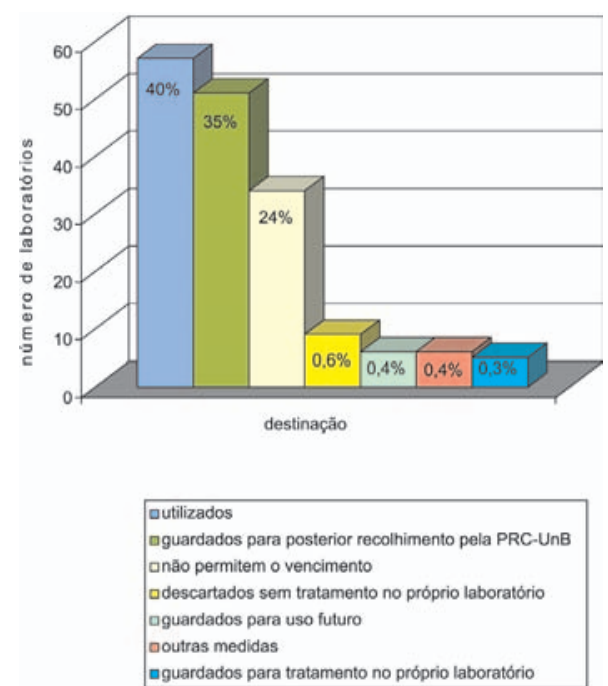

Figura 7. Destinação dos reagentes vencidos

utilização ainda maior não poderia ser feita, já que a "validade" de um produto químico deveria estar associada a uma análise de controle de qualidade que justificasse o descarte do reagente pela perda de suas características físico-químicas. Desta forma, o tratamento de reagentes "vencidos" recupera sua qualidade, o que significa não só economia de recursos financeiros, mas também de recursos naturais - observando que o meio ambiente atua fornecendo insumos e recebendo rejeitos quando da destinação final ${ }^{11-13}$. Vê-se, portanto, que informação e conhecimento técnico são imprescindíveis para uma (re)utilização racional desse tipo de material. 
Cerca de $61 \%$ dos laboratórios investigados ainda lançam seus resíduos "pia abaixo" ou em lata de lixo (Figura 8). Esse percentual é demasiadamente elevado, sendo provavelmente oriundo de um profundo desconhecimento da natureza do resíduo por parte do gerador. Vê-se, no entanto, um embrião de preocupação com a correta destinação dos resíduos, já que pelo menos $30 \%$ dos laboratórios geradores separam seus resíduos para posterior recolhimento e armazenagem no depósito de resíduos químicos.
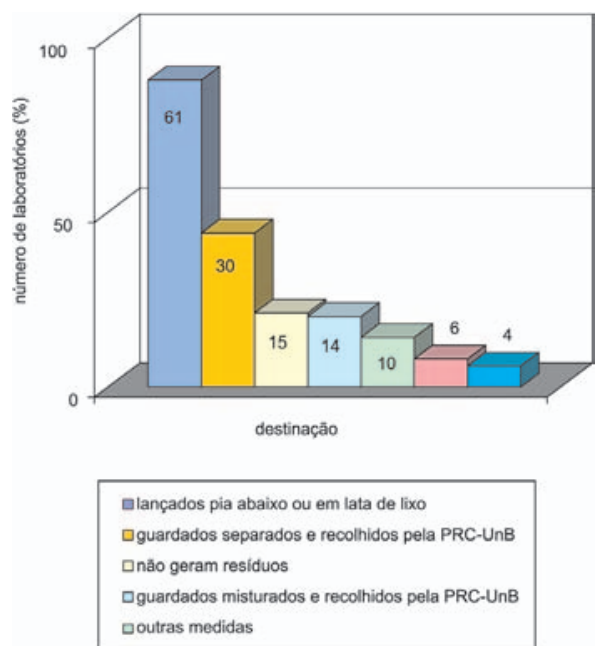

Figura 8. Destinação dos resíduos gerados pelos laboratórios

Observa-se na Figura 9 que mais de $70 \%$ dos laboratórios geram menos de $10 \mathrm{~L}$ de resíduos por mês, o que mostra o perfil típico de resíduos gerados em instituições de ensino: pouca quantidade e grande diversidade. Essa pequena quantidade per capita de resíduos gerados, no entanto, merece considerações mais cuidadosas, tendo em vista o grande número de laboratórios em atividade. Outro ponto fundamental a ser considerado na avaliação deste resultado é que, como boa parte dos laboratórios lança seus resíduos na pia, não se pode afirmar que há um controle efetivo do volume de resíduo químico gerado pelo laboratório.

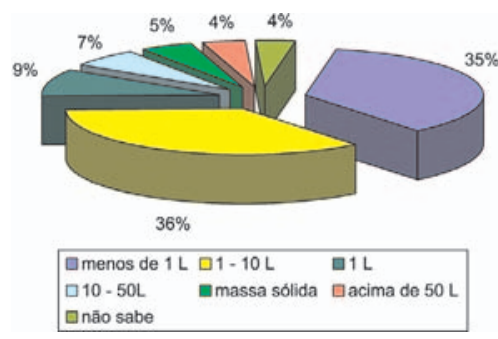

Figura 9. Volume mensal de resíduos gerados por laboratório

A Figura 10 e a Tabela 1 mostram a relação existente entre volume de resíduos gerados e a destinação inadequada desses - quer "pia abaixo" ou em lixo comum. Praticamente todo o resíduo gerado com volume de até 10 L é lançado "pia abaixo". O mesmo também ocorre em laboratórios que geram volumes mensais de resíduos superiores a 50 L. Do material sólido, cerca de $40 \%$ também é descartado de forma inadequada, em lixo comum. Atualmente, a UnB recolhe em seu depósito de resíduos químicos entre 6 e 8 t de resíduos a cada dois anos, provenientes de suas diferentes unidades. Portanto, os resultados comprovam que essa quantidade recolhida subestima - e muito - a geração real de resíduos da Universidade, pois nossos estudos mostram que ainda existem vários geradores que descartam grande parte de seus resíduos diretamente nas pias ou em lixo comum. Este fato também pode ser comprovado quando se compara o número de geradores de resíduos químicos levantado nas entrevistas - cerca de 140 geradores - e o número de geradores efetivamente cadastrados junto à UTReQ - cerca de 20 geradores - (dados referentes ao primeiro ano de implantação do programa de gerenciamento de resíduos químicos).

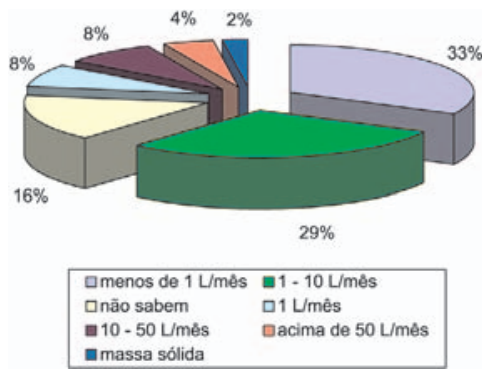

Figura 10. Volume de resíduos descartados na rede de esgoto ou em lixo comum

Tabela 1. Geração e lançamento inadequado de resíduos

\begin{tabular}{lccc}
\hline $\begin{array}{l}\text { Quantidade } \\
\text { gerada }\end{array}$ & Geração (\%) & $\begin{array}{c}\text { Lançamento “pia” } \\
\text { e esgoto }(\%)\end{array}$ & $\begin{array}{c}\text { Lançamento } \\
\text { inadequado/geração (\%) }\end{array}$ \\
\hline$<1,0 \mathrm{~L}$ & 35 & 33 & 94 \\
$1-10 \mathrm{~L}$ & 45 & 37 & 82 \\
$10-50 \mathrm{~L}$ & 7 & 8 & $*$ \\
$>50 \mathrm{~L}$ & 4 & 4 & 100 \\
Massa sólida & 5 & 2 & 40 \\
Não sabem & 4 & 16 & $* *$ \\
\hline
\end{tabular}

* Resultado superior a $100 \%$, resultante provavelmente de estimativas dentro da margem de erro do procedimento. Na realidade, significaria $100 \%$ de lançamento inadequado; ** apesar de somente $4 \%$ dos informantes declarar não saber estimar a quantidade de resíduos gerados, cerca de $16 \%$ diz não saber estimar a quantidade lançada de forma inadequada. Este resultado pode ser oriundo de uma tentativa de se "mascarar" esse procedimento incorreto, em uma tentativa de evitar comprometimento do laboratório.

Dos laboratórios que armazenam seus resíduos para serem recolhidos posteriormente foram obtidos, também, dados sobre o tempo de permanência dos recipientes na unidade geradora até que sejam coletados por órgão responsável (Prefeitura do Campus, nos casos analisados). Estes dados são mostrados na Figura 11.

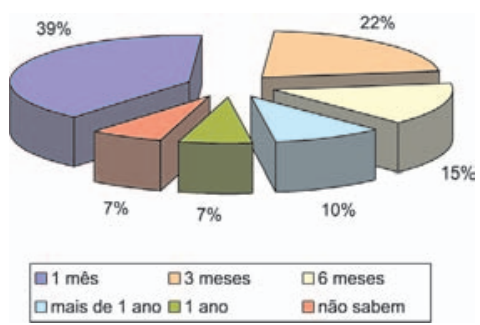

Figura 11. Tempo de armazenamento de resíduos nos laboratórios até coleta

Em todos os laboratórios que armazenam resíduos foram analisados, ainda, os tipos de recipientes utilizados por eles, sendo os resultados apresentados na Figura 12. Alguns destes podem utilizar mais de um tipo de recipiente. 


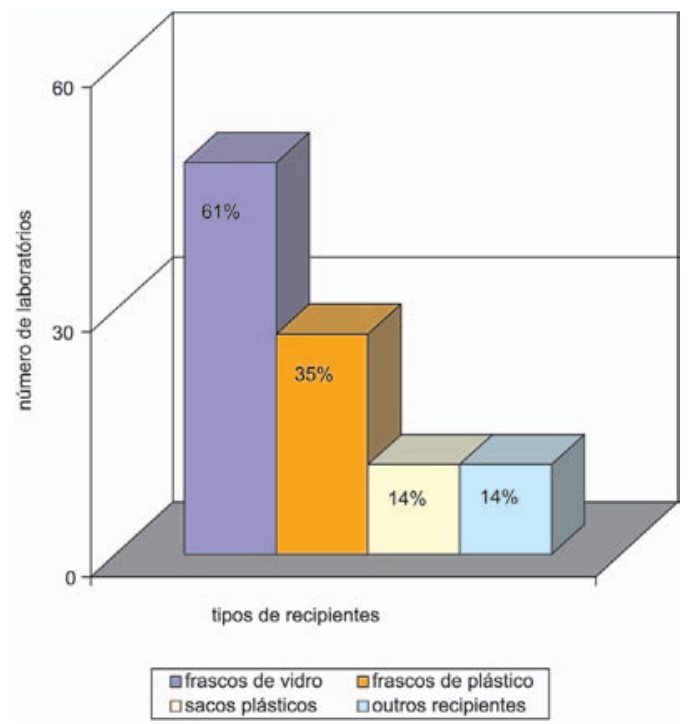

Figura 12. Tipos de recipientes usados para armazenar resíduos

As informações contidas em rótulos anexos aos recipientes de armazenamento são de suma relevância (Figura 13). Ao se descartar um resíduo, é importante que este esteja identificado adequadamente pelo seu gerador, com o fim de receber tratamento correto ou ser utilizado por outras unidades ou, mesmo, ser incinerado por um custo menos elevado.

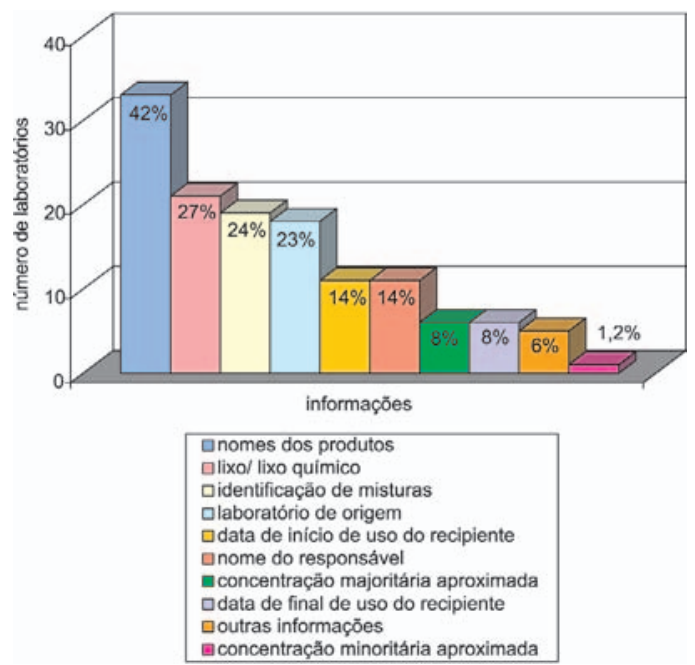

Figura 13. Informações contidas sobre os recipientes em que se armazenam resíduos nos laboratórios

\section{CONSIDERAÇÕES FINAIS}

A criação de uma central de tratamento, recuperação e destinação final de resíduos químicos gerados na UnB é parte fundamental nesta nova concepção de gerenciamento ambiental de resíduos ${ }^{14}$. Além de executar as atividades precípuas para as quais está sendo projetada, ressalta-se ainda a previsão de um alcance social de grande magnitude para ações oriundas de desdobramentos naturais de nossas ações futuras, nas áreas de ensino, extensão e pesquisa.

1. Atividades de ensino: formação de recursos humanos especializados em tratamento e gerenciamento de resíduos em nível de graduação, com implantação de disciplinas específicas e oferecimento de estágios.
2. Atividades de extensão: oferecimento de serviços à comunidade, por meio da disponibilização de gerenciamento e tratamento de resíduos químicos a diversas entidades públicas e privadas do Distrito Federal e em torno; programas de apoio à inserção social de pessoas sem qualificação profissional específica, que serão treinadas em atividades na Central; compartilhamento com a sociedade de conceitos fundamentais de gestão ambiental de resíduos, por meio da oferta de cursos à comunidade.

3. Atividades de pesquisa: englobam desenvolvimento e otimização de métodos para tratamento de resíduos orgânicos e inorgânicos. Nosso objetivo é minimizar o descarte final de resíduos, reduzindo custos tanto financeiros quanto ambientais. Uma linha de pesquisa refere-se à degradação de corantes sintéticos por meio do processo oxidativo avançado (POA) denominado fotocatálise heterogênea, empregando um material com propriedades semicondutoras como catalisador $(\mathrm{ZnO})$ e fonte de radiação (luz solar e lâmpadas fluorescentes comerciais) $)^{15,16}$

Outra linha de pesquisa é a adsorção de metais potencialmente tóxicos, como cromo, zinco e cobre, em MDF ("middle density fiber" - fibra de média densidade), material usado na indústria moveleira ${ }^{17}$.

Desta forma, as atividades de pesquisa têm propiciado a formação de recursos humanos especializados em tratamento e gerenciamento de resíduos em nível de pós-graduação, com implantação de disciplinas para cursos de gestão ambiental já existentes.

\section{REFERÊNCIAS}

1. Matos, J. G. S.; Lima, B. A. F.; Shintaku, S. F.; Guaritá-Santos, A. J. M.; Imbroisi, D.; Machado, P. F. L.; Resumos do II Encontro Centro-Oeste de Química/XII Encontro Centro-Oeste de Ensino de Química, Brasília, Brasil, 2002.

2. Imbroisi, D.; Guaritá-Santos, A. J. M.; Monteiro, H. J.; Tinoco, C. J.; Moreira, L. L.; Anais do VIII Encontro Nacional sobre Gestão Empresarial e Meio Ambiente, Rio de Janeiro, Brasil, 2005.

3. Cunha, C. J.; Quim. Nova 2001, 24, 424.

4. Amaral, S. T.; Machado, P. F. L.; Peralba, M. C.; Camara, M. R.; Santos, T.; Berleze, A. L.; Falcão, H. L.; Martinelli, M.; Gonçalves, R. S.; Oliveira, E. R.; Brasil, J. L.; Araújo, M. A.; Borges, A. C.; Quim. Nova 2001, 24, 419.

5. Alberguini, L. B. A.; Silva, L. C.; Rezende, M. O. O.; Quim. Nova 2003, 26, 291.

6. http://lqd.iqm.unicamp.br/pdf/LivroCap.11.pdf, acessada em Maio 2003.

7. http://www.usp.br/siicusp/8osiicusp/resumos/ficha1395.htm, acessada em Novembro 2003.

8. Tavares, A. G.; Bendassolli, J. A.; Máximo, E.; Ignoto, R. F.; Quim. Nova 2003, 26, 612 .

9. Guaritá-Santos, A. J. M.; $1^{\text {st }}$ International Symposium on Residue Management in Universities, Santa Maria, Brasil, 2202.

10. Guaritá-Santos, A. J. M.; Imbroisi, D.; Megid, J. B.; Workshop "Gerenciamento de Resíduos Químicos em Pesquisa e Ensino”, Poços de Caldas, Brasil, 2001.

11. Imbroisi, D.; $2^{\circ}$ Encontro Nacional de Segurança em Laboratórios Químicos, Porto Alegre, Brasil, 2002.

12. Müeller, C. C.; Manual de Economia do Meio Ambiente, Brasília: Brasil, 2001.

13. Bellia, V.; Introdução à Economia do Meio Ambiente, IBAMA: Brasília, Brasil, 1996.

14. Afonso, J. C.; Noronha, L. A.; Felipe, R. P.; Freidinger, N.; Quim. Nova $\mathbf{2 0 0 3}, 26,602$

15. Shintaku, S. F.; Dissertação de Mestrado, Universidade de Brasília, Brasil, 2005.

16. Shintaku, S. F.; Imbroisi, D.; Guaritá-Santos, A. J. M.; Resumos do XLIV Congresso Brasileiro de Química, Fortaleza, Brasil, 2004.

17. Barbosa, S. S.; Imbroisi, D.; Guaritá-Santos, A. J. M.; Resumos do XLIV Congresso Brasileiro de Química, Fortaleza, Brasil, 2004. 


\section{ANEXO - QUESTIONÁRIO APLICADO AOS LABORATÓRIOS}

UNIVERSIDADE DE BRASÍLIA- UnB

INSTITUTO DE QUÍMICA - IQ

COMISSÃO (entrevistador)

Professores Orientadores: Antônio José Moraes Guarita dos Santos Denise Imbroisi

Patrícia Lootens Machado

Gerenciamento de Resíduos Químicos na Universidade de Brasília

Centro de Custo:

Laboratório:

Localização:

Caixa Postal:

Telefone:

Ramal:

Professor responsável: e-mail:

Técnico responsável: e-mail:

Entrevistado:

Função:

\section{Questionário}

1. Neste laboratório utiliza-se alguma substância química (produto químico)?

( ) $\operatorname{sim}(\quad)$ não

2. Que tipo de substâncias químicas são utilizadas?

( ) ácidos

( ) bases

( ) metais (sólidos ou soluções)

( ) solventes orgânicos:

( ) halogenados

( ) não-halogenados

( ) sais

( ) óxidos

( ) tintas

( ) outros

3. Onde são armazenados os reagentes utilizados no laboratório?

( ) almoxarifado externo (fora do laboratório)

( ) dentro do próprio laboratório

( ) almoxarifado externo e dentro do próprio laboratório

( ) outro local

4. O que é feito com reagentes vencidos?

( ) utilizados

( ) descartados sem tratamento pelo próprio laboratório

( ) guardados para uso futuro (doação, por exemplo)

( ) guardados para posterior tratamento no próprio laboratório

( ) guardados para posterior recolhimento pela prefeitura da universidade

( ) não permitem o vencimento

( ) outras medidas
5. O que é feito com resíduos químicos gerados no laboratório?

( ) não geram resíduos

( ) lançado pia abaixo ou em lata de lixo comum

( ) guardados para posterior tratamento pelo próprio laboratório

( ) guardados misturados para recolhimento pela prefeitura

( ) guardados separados para posterior recolhimento pela prefeitura

( ) reutilizam

( ) outras medidas

6. Qual o tempo de armazenamento de resíduos até o recolhimento por órgão responsável?

( ) 1 a 2 meses

( ) 3 a 5 meses

( ) 6 a 11 meses

( ) 1 ano

( ) mais de um ano. Especifique:

( ) não sabem informar

7. Como são estocados os resíduos guardados?

( ) frascos de plástico

( ) frascos de vidro

( ) sacos plásticos

( ) outros recipientes. Especifique:

8. Quais as informações contidas nos rótulos dos recipientes de resíduos?

( ) lixo/ lixo químico

( ) identificação de misturas

( ) nomes dos produtos químicos

( ) laboratório de origem

( ) data de início do uso do recipiente para armazenamento de resíduos

( ) data de final do uso do recipiente para armazenamento de resíduos

( ) nome do responsável

( ) concentração majoritária aproximada (componente principal)

( ) concentração minoritária aproximada (componentes secundários)

( ) outras informações. Listar:

9. Qual o volume mensal de resíduos gerados?

( ) menos de $1 \mathrm{~L}$

( ) $1-10 \mathrm{~L}$

( ) $10-50 \mathrm{~L}$

( ) acima de 50 L. Especifique:

( ) massa sólida

( ) não sabem informar.

10. Caso seja tratado algum resíduo no laboratório, identifique-os e o tratamento adotado.

\begin{tabular}{|l|l|}
\hline Tipo de resíduo & Tratamento adotado \\
\hline & \\
\hline & \\
\hline & \\
\hline
\end{tabular}

